\title{
Article
}

\section{Interactions at the peptide/silicon surfaces - Evidence of peptide multilayer assembly}

Zsuzsanna Pápa, Sathish Kumar Ramakrishnan, Marta Martin, Thierry Cloitre, Laszlo Zimanyi, Jessica Marquez, Judit Budai, Zsolt Toth, and Csilla Gergely

Langmuir, Just Accepted Manuscript • DOI: 10.1021/acs.langmuir.6b00916 • Publication Date (Web): 17 Jun 2016

Downloaded from http://pubs.acs.org on June 18, 2016

\section{Just Accepted}

"Just Accepted" manuscripts have been peer-reviewed and accepted for publication. They are posted online prior to technical editing, formatting for publication and author proofing. The American Chemical Society provides "Just Accepted" as a free service to the research community to expedite the dissemination of scientific material as soon as possible after acceptance. "Just Accepted" manuscripts appear in full in PDF format accompanied by an HTML abstract. "Just Accepted" manuscripts have been fully peer reviewed, but should not be considered the official version of record. They are accessible to all readers and citable by the Digital Object Identifier (DOI®). "Just Accepted" is an optional service offered to authors. Therefore, the "Just Accepted" Web site may not include all articles that will be published in the journal. After a manuscript is technically edited and formatted, it will be removed from the "Just Accepted" Web site and published as an ASAP article. Note that technical editing may introduce minor changes to the manuscript text and/or graphics which could affect content, and all legal disclaimers and ethical guidelines that apply to the journal pertain. ACS cannot be held responsible for errors or consequences arising from the use of information contained in these "Just Accepted" manuscripts. 


\section{Interactions at the peptide/silicon surfaces -} Evidence of peptide multilayer assembly

Zsuzsanna Pápa ${ }^{a^{*}, \text { Sathish Kumar Ramakrishan }}{ }^{b, c^{*}}$, Marta Martin ${ }^{b}$, Thierry Cloitre $^{b}$, László Zimányi ${ }^{d}$, Jessica Márquez ${ }^{d, e}$, Judit Budai ${ }^{a}$, Zsolt Toth ${ }^{f}$, Csilla Gergely ${ }^{\text {\#\# }}$

${ }^{a}$ Department of Optics and Quantum Electronics, University of Szeged, Szeged, Hungary.

${ }^{b}$ Laboratoire Charles Coulomb (L2C), UMR 5221 CNRS-Université de Montpellier, Montpellier, France.

${ }^{\mathrm{c}}$ Nanobiology Institute, Yale University, West Haven, CT, United States

${ }^{d}$ Institute of Biophysics, Biological Research Centre of the Hungarian Academy of Sciences, Szeged, Hungary

${ }^{e}$ Faculty of Chemical Sciences, Universidad Autónoma de San Luis Potosí, San Luis Potosí, Mexico

${ }^{\mathrm{f}}$ Department of Oral Biology and Experimental Dental Research, University of Szeged, Szeged, Hungary

*These authors contributed equally to this work.

KEYWORDS: ellipsometric evaluation, peptide layer, patterned layer, atomic force microscopy, surface coverage 


\begin{abstract}
Selective deposition of peptides from liquid solutions to $\mathrm{n}$ - and p-doped silicon has been demonstrated. The selectivity is governed by peptide/silicon adhesion differences. A noninvasive, fast characterization of the obtained peptide layers is required to promote their application for interfacing silicon-based devices with biological material. In this study we show that spectroscopic ellipsometry - a method increasingly used for the investigation of biointerfaces - can provide essential information about the amount of adsorbed peptide material and the degree of coverage on silicon surfaces. We observed the formation of peptide multilayers for a strongly binding adhesion peptide on p-doped silicon. Application of the patterned layer ellipsometric evaluation method combined with Sellmeier-dispersion led to physically consistent results, which describe well the optical properties of peptide layers in the visible spectral range. This evaluation allowed the estimation of surface coverage, which is an important indicator of adsorption quality. The ellipsometric findings were well supported by atomic force microscopy results.
\end{abstract}




\section{Introduction}

Hybrid systems constituted by inorganic materials interfaced with peptides or proteins resulted in the emergence of new, promising applications for directed materials engineering, nanophotonics and bionanotechnology. ${ }^{1-3}$ Due to their technological versatility, silicon (Si) containing materials and nanostructured silicon materials such as nanocrystals, nanorods, nanowires, and porous silicon have become increasingly popular for applications in storage, batteries and sensing devices. ${ }^{4-6}$ Control of Si surface chemistry is crucial either for fabricating electronic devices or to couple organic molecules for sensing. However, device functionality can be seriously limited by complex phenomena at the solid/liquid interface often resulting in a loss of activity of biological molecules due to their unfolding upon immobilization. Therefore, various surface modification strategies are employed to avoid unwanted denaturation of biomolecules when adsorbed on Si. Classical chemical methods of functionalization raise concerns related to toxic effects, loss of biomolecule activity or binding affinities. ${ }^{7}$ Bio-inspired routes for controlling surface chemistry and morphology overcome these drawbacks and provide high level of integration and miniaturization from nano to millimetric scale. Peptide-route functionalization of Si with small peptides by simple adsorption provides a satisfying solution in terms of control of the extent of surface modification, of selectivity and ease of implementation compared to other surface modification strategies. ${ }^{8-11}$ Combinatorial phage libraries are widely used to isolate high affinity peptides against a given target material. ${ }^{12,13}$ Selective recognition mechanisms of the isolated peptides are well exploited to engineer functional hybrid materials, but the underlying molecular mechanism remains unknown.

Numerous theoretical studies addressed the mechanism of adhesion between peptide and inorganic substrate. ${ }^{14-17}$ In a recent work of our group, ${ }^{18}$ we investigated the adsorption on the ntype silicon of three 12-mer peptides that were previously elaborated by phage display technology (P1, P2 and P3, see Table 1). ${ }^{8}$ Molecular dynamics simulations have been performed to reveal the organization of the peptides on the surface and to identify the amino acids 
responsible for stronger binding based on the distance to the surface. We have shown that both the amino acid sequence and the molecular architecture of the peptide are key determinants for the selective binding of peptides onto Si. According to the calculations, in the case of $\mathrm{n}^{+}$-type $\mathrm{Si}$, P2 showed better adhesion than P1, whereas in the case of $\mathrm{p}^{+}$-type $\mathrm{Si}$, the best binding properties could be predicted for the P3 peptide.

Although theoretical studies can provide the understanding of the molecular assembly processes and dynamics at the level of single amino acid or peptide, the reliability of simulation models is dependent on the accuracy of the force field parameters used. Silicon is a very challenging material to model due to its heterogeneity and tendency of forming oxide upon immediate exposure to air or water. Available force fields are entirely dependent on parameterization based on the bulk properties of silicon and have not been validated to study biomolecule-inorganic interface. ${ }^{19-21}$ Significant developments were made in the past, ${ }^{22}$ but a reliable force field is yet to be developed based on experimental evidence. The challenge is to validate the calculated peptide structure, its surface recognition efficiency and the percentage of coverage, as yet there are no published experimental data available to test the accuracy of the theoretical results. Techniques such as ellipsometry, atomic force microscopy (AFM) or Fourier transform infrared spectroscopy in attenuated total reflection mode (ATR-FTIR) can provide meaningful data for surface coverage, which can be used in theoretical calculations. Ellipsometry is increasingly employed to investigate protein layers in both the visible and the infrared spectral range due to its detection sensitivity and flexibility. ${ }^{23,24}$ Ellipsometric evaluation provided a wealth of information such as thickness and structure of the layers, and their optical properties. ${ }^{25-27}$ On the other hand, AFM was previously employed to calculate the peptide adhesion coefficient on silica surface and subsequently validated with theoretical simulations. ${ }^{28}$ Merging information from several experimental methods facilitates the development of accurate and reliable force fields for theoretical calculations.

Our previous theoretical and experimental findings revealed specific adhesion trends for some peptides against $\mathrm{n}^{+}$and $\mathrm{p}^{+}-\mathrm{Si}$ substrates. The sequences of the investigated peptides presenting different levels of affinity for these substrates are listed in Table 1. While the P1 peptide displayed similar adherence to both types of Si, P2 and P3 peptides showed higher affinity for $\mathrm{n}^{+}$ and $\mathrm{p}^{+}-\mathrm{Si}$, respectively. The PC4 peptide was also studied as a truncated variant of P3 exhibiting 
enhanced adhesion for $\mathrm{p}^{+}-\mathrm{Si}^{29}$ The biotinylated forms (using a GGSK linker) of the P1 and P3 peptides were also considered as these molecules can be used to detect various streptavidinassociated species. ${ }^{8}$ With the aim to comprehend and control the design of peptide-silicon interfaces, we now performed spectroscopic ellipsometry and AFM experiments providing information on the refractive index, thickness, and surface coverage of peptide layers on n-type and p-type silicon.

Table 1. Sequence of peptides exhibiting high affinity for $\mathrm{n}^{+}$, or $\mathrm{p}^{+}-$type silicon as obtained by the phage display technique ${ }^{8}$ and/or synthesized according to the notations in references 18 (P1, $\mathrm{P} 2, \mathrm{P} 3)$ and 27 (PC4). ${ }^{\mathrm{a}}$ The isoelectric point values were calculated using the $\mathrm{pI} / \mathrm{Mw}$ tool at http://expasy.org.

\begin{tabular}{|c|c|c|}
\hline Peptides & Surface & $p I^{a}$ \\
\hline SVSVGMKPSPRP (P1) & $\mathrm{n}^{+}, \mathrm{p}^{+}-\mathrm{Si}$ & 11 \\
\hline LLADTTHHRPWT (P2) & $\mathrm{n}^{+}-\mathrm{Si}$ & 6.92 \\
\hline SPGLSLVSHMQT (P3) & $\mathrm{p}^{+}-\mathrm{Si}$ & 6.46 \\
\hline SLVSHMQT (PC4) & $\mathrm{p}^{+}-\mathrm{Si}$ & 6.46 \\
\hline SVSVGMKPSPRP-GGSK- biotin (P1-B) & $\mathrm{n}^{+}, \mathrm{p}^{+}-\mathrm{Si}$ & 11.17 \\
\hline SPGLSLVSHMQT-GGSK-biotin (P3-B) & $\mathrm{p}^{+}-\mathrm{Si}$ & 8.49 \\
\hline
\end{tabular}

\section{Materials and Methods}

\subsection{Peptides}

Prior to this work, a phage display 12 mer peptide library was used to isolate the specific peptides against $\mathrm{n}^{+}$and $\mathrm{p}^{+}$silicon surfaces. ${ }^{8}$ Based on their obtained sequences, peptides were synthesized by the standard solid phase peptide synthesis (SPPS) method using Fmoc chemistry on Fmoc 
Rink amide PS resin. The synthesis of biotinylated peptides, P1B and P3B, was reported in our previous work. ${ }^{29}$ The synthesized crude peptides were purified by high performance liquid chromatography and analyzed by LC/MS, 1H, and 13C NMR and used without further purification. Absorbance of the peptides diluted in phosphate-buffered saline solution containing $0.1 \%$ Tween-20 (130 mM PBST/10) at $20 \mu \mathrm{M}$ concentration was measured with a UV/vis (UNICAM UV4) spectrophotometer in the 2.5-6.5 eV range using a $1 \mathrm{~cm}$ cuvette.

\subsection{Peptide adsorption on silicon}

Silicon (100) wafers, highly doped by either boron $\left(\mathrm{p}^{+}\right)$or phosphorous $\left(\mathrm{n}^{+}\right)$, were first exposed to $\mathrm{HF}$ for $10 \mathrm{~min}$ to remove native oxide, then rinsed with deionized water for one minute. The surfaces were then incubated with the synthesized peptides at $20 \mu \mathrm{M}$ concentration diluted in $130 \mathrm{mM}$ PBS solution containing $0.1 \%$ Tween-20 (PBST/10) in presence of $0.1 \%$ bovine serum albumin (BSA) for 2 hours. The role of Tween and BSA was to prevent nonspecific interactions on the surface. Then a thorough rinsing step in PBST/10 and distilled water was performed to remove unbound peptides. The samples were then gently dried with $\mathrm{N}_{2}$ before recording their reflectivity spectra.

\subsection{Spectroscopic ellipsometry}

Spectroscopic ellipsometry measures the complex reflectance ratio, $\rho$, as a function of photon energy (wavelength), which is described by two angles ( $\Psi$ and $\Delta$ ) according to the following equation:

$$
\rho=r_{p} / r_{s}=\operatorname{tg}(\Psi) e^{i \Delta}
$$

where $r_{p}$ and $r_{s}$ are the reflectance of the light polarized parallel and perpendicular to the plane of incidence, respectively, $\operatorname{tg}(\Psi)$ is the amplitude of $\rho$, while $\Delta$ is its phase. $\rho$ is in correlation with the optical properties of bulk materials, which are characterized by the refractive index - $n$, and the extinction coefficient - $k$ or, equivalently, by the real and imaginary parts of the complex dielectric function ( $\varepsilon_{1}$ and $\varepsilon_{2}$, respectively). In case of single- or multilayers on a bulk substrate, the polarization state of reflected light depends on the structure and the thickness(es) of the layer(s) besides their optical properties. To obtain the characteristics of the investigated samples, their structural and optical properties have to be modeled. During an indirect fitting procedure 
the $n, k$ and thickness values in the model are varied until an appropriate fit of the measured $\Psi$ and $\Delta$ spectra is found based on the Mean Square Error (MSE) value. ${ }^{30}$ If appropriate MSE values are reached, the actual $n, k$ and thickness values of the model are considered as the ones of the investigated sample.

In this study, $\Psi$ and $\Delta$ values were measured as a function of the photon energy using a Woollam M2000 rotating compensator ellipsometer in the range of 1.24-5 eV (1000-248 nm). Angles of incidences were chosen close to the Brewster angle of silicon; $65^{\circ}, 70^{\circ}$ and $75^{\circ}$. The samples were gently dried and then measured at three different positions (size of the illuminated spot was in the range of a few $\mathrm{mm}^{2}$ ). Measurement errors arise from the standard deviations of the evaluation results of these different measurement positions for a given sample. Analysis of the spectra was performed using the WVASE32 software.

\subsection{Atomic force microscopy}

AFM images on samples prepared in the same way as for ellipsometry were recorded in air using an Asylum MFP-3D head equipped with a Molecular Force Probe 3D controller (Asylum Research, Santa Barbara, CA, USA). Tapping (AC) mode was selected as the imaging mode, and rectangular silicon nitride cantilevers from Olympus (OMCL-AC160TM, Tokyo, Japan) with a spring constant of $4 \mathrm{nN} / \mathrm{nm}$ were employed. The spring constant was determined using the thermal noise method within the software supplied. Height, amplitude, and phase images were recorded. In the last mode, compositional variations were measured by the phase lag of the vibrating probe with respect to the external excitation. Phase lag of the oscillation allows us to explore tip-surface elastic and inelastic interactions, giving a qualitative measure of the energy dissipation involved in the contact between the tip and the sample, which depends on a number of factors, including viscoelasticity, adhesion, variations in composition, hardness and the chemical nature of the sample. Several trace and retrace scans were performed over a given surface area to ensure reproducible images. The images were typically taken at $1 \mathrm{~Hz}$ scan rate and digitized in $512 \times 512$ pixels. They were first recorded at $80 \times 80 \mu^{2}$, and then at $20 \times 20 \mu \mathrm{m}^{2}$ to achieve better resolution. At least three $20 \times 20 \mu \mathrm{m}^{2}$ images of different zones were recorded and used for the statistical analysis for each sample. Covered surface ratios were also calculated using the supplied software. 


\section{Results and discussion}

\subsection{Absorbance measurements}

Since ellipsometry is an indirect measurement technique, the final results strongly depend on the applied model. In order to find the appropriate ellipsometric model it is useful to perform some independent measurements on the investigated samples. First, the absorbance of the peptide solutions was determined (Fig. 1).

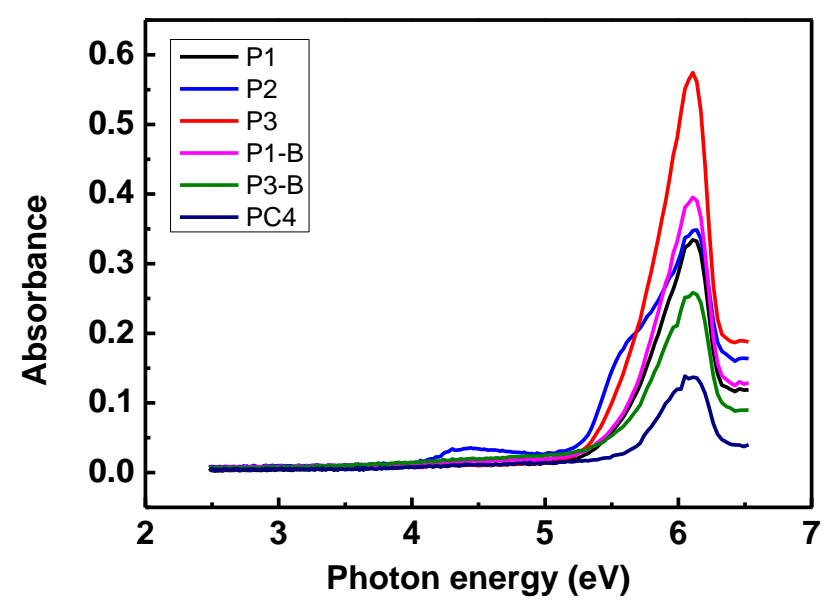

Fig. 1: Absorbance spectra of the peptide solutions. Strong absorption peaks are only present in the UV region, outside the spectral range covered by ellipsometry. For the abbreviations in the legend, see table 1.

According to the absorbance measurements, the peptide solutions can be considered transparent under $5 \mathrm{eV}$, i.e. in the spectral range of ellipsometric measurements. Based on these results, a transparent layer can be assumed in the ellipsometric model, which is a good starting point for modeling. 


\subsection{Ellipsometry}

\section{$\Psi$ and $\Delta$ curves}

In Fig. 2 (a) and (b), $\Psi$ and $\Delta$ curves are shown as measured on n-type and p-type silicon surfaces before and after coating (as for example) with P3 peptide. The same measurements were performed for all the peptides listed in table 1. It was emphasized earlier that to get exact information from ellipsometric measurements, an optical model needs to be built. However, the difference between the curves measured before and after peptide deposition can already provide certain useful information.
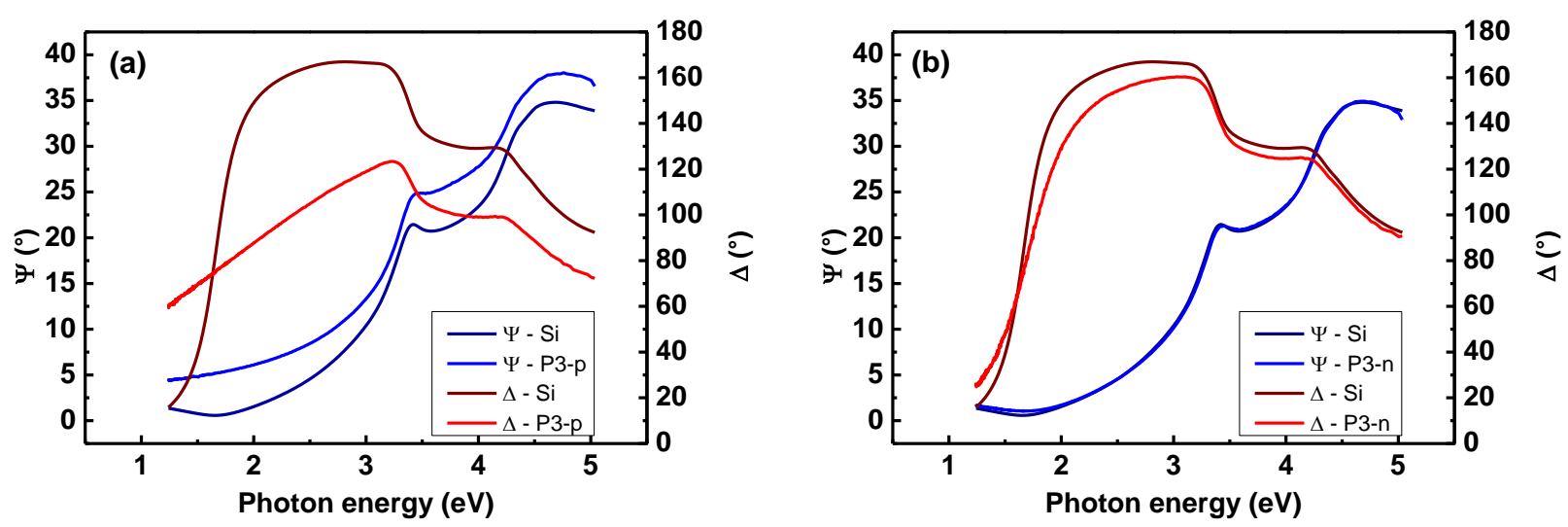

Fig. 2: $\Psi$ and $\Delta$ curves related to P3 peptide deposited onto p-type (a) and n-type silicon (b). Data of uncoated silicon are also presented in both cases.

Clear differences versus $\Psi$ and $\Delta$ of uncoated silicon are observable in the case of the P3 peptide deposited onto the p-type substrate. Much smaller differences between the curves correspond to smaller polarization changes caused by the peptide layer on n-type Si. This can be related to the optical properties and the amount of the deposited material. Assuming that peptides have similar optical properties on the $\mathrm{p}$ and n-type Si surfaces, the observed changes indicate different amounts of material deposited onto p-type or n-type Si surfaces. Note that $\Delta$ values follow more sensitively the changes on the sample surface, as has been shown earlier for rough Si surfaces and even for proteins as well. ${ }^{31,32}$ 
If the difference between the data of uncoated silicon and the data measured on peptide layers are plotted for each peptide (table 1) deposited onto p- and n-type substrates, one can have a first insight into the binding affinity of the peptides (Fig. 3).
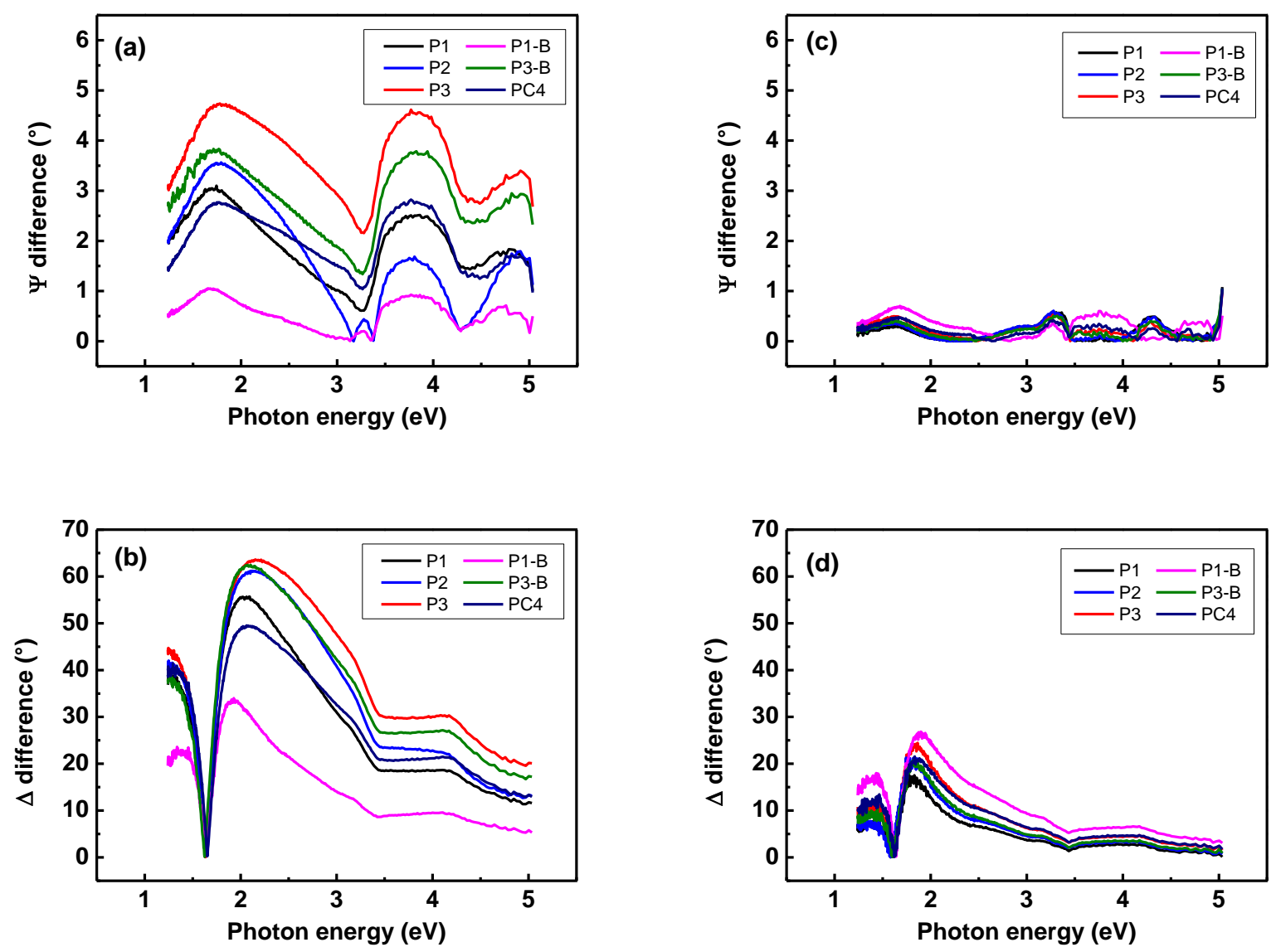

Fig. 3: Difference between the $\Psi$ and $\Delta$ spectra of uncoated silicon and samples coated with peptide layers. Graphs (a) and (b) show $\Psi$ and $\Delta$ differences measured on p-type silicon samples, and graphs (c) and (d) relate to n-type silicon samples. For easier comparison, the differences of $\Psi$ curves and differences of $\Delta$ curves are plotted using the same scale for all the substrates.

In the case of p-type substrates, the changes are much larger than in the case of n-type substrates, which indicate a more efficient binding of the investigated peptides to p-type silicon. By considering only the differences measured on p-type samples, it can be stated that the largest effect relates to P3 peptide, and the weakest adhesion can be observed in the case of P1-B peptide. 


\section{Ellipsometric evaluation of peptide layers}

During sample preparation, silicon substrates were treated with hydrofluoric acid in order to remove the native oxide layer. After oxide removal, two differently doped control samples (a ptype and an n-type) were measured with ellipsometry, and the others were coated with peptides. The native oxide layer builds up very rapidly on the surface so its thickness cannot be considered as zero. Oxide thickness measurements on both p-and n-type control samples resulted close to 1 nm (p-type: $0.913 \mathrm{~nm}$, n-type: $1.064 \mathrm{~nm}$ ), so the thickness of the native oxide layer was fixed at $1 \mathrm{~nm}$ during the evaluation process.

The applied ellipsometric model consisted of the silicon substrate (optical data from ${ }^{33}$ ), the native oxide layer and the peptide layer.

Based on the results of the absorbance measurements, a dispersion law suitable for transparent materials was used to describe the optical behavior of peptide layers. The Sellmeier-dispersion relation is defined by the following formulas ${ }^{34}$

$$
\varepsilon_{1}(E)=n^{2}(E)=\varepsilon_{\infty}+\sum_{n=1}^{2} \frac{A_{n}}{E_{n}{ }^{2}-E^{2}} \quad \varepsilon_{2}(E)=0
$$

It describes the refractive index dispersion, as a function of photon energy (E) of transparent materials by using absorption peaks (poles) outside the investigated spectral range. The curvature of $\varepsilon_{1}$ is determined by the amplitude $\left(A_{n}\right)$ and by the position $\left(E_{n}\right)$ of the absorption peak while the absolute value can be tuned by adding an offset $\left(\varepsilon_{\infty}\right)$. In case of application of Sellmeierdispersion, the Kramers-Kroenig relations, which ensure that the resulting optical properties do not lead to unphysical results, are fulfilled automatically. However, by modeling the optical properties of the peptide layers with Sellmeier dispersion relations, the MSE values remained high, and the measured and fitted curves did not overlap properly (see Supplementary information). This model deals with perfect layers (i.e. layers defined by parallel interfaces and not showing any discontinuity), while proteins, for instance, often aggregate and do not form a continuous layer. ${ }^{35}$ Therefore, the ellipsometric model was extended with an island-like (patterned) character of the peptide layer. This second model contains again a non-absorbing layer, but it is assumed that the layer does not cover perfectly the substrate. The optical properties of the peptides were modeled in the framework of this patterned layer model again 
with Sellmeier dispersion relations. Concerns might arise on the eventual optical anisotropy inside organic multilayers as reported for protein (flagellin) films ${ }^{36}$ containing chain-like domains, positioned perpendicular to the surface. In our case, the investigated peptides are very small, containing only 12 aminoacids so the formation of fibrous, chain-like structures can be excluded and anisotropy can be neglected during modeling.

To model the partial coverage of the films, the so-called patterned layer tool was applied in the WVASE32 software. In case of a patterned layer the observed polarization change is partially originating from areas where both the top peptide layer and the native oxide underlayer are present, and from areas where there is no peptide. Reflection from different layer structures causes different polarization changes that are averaged within the model. The percentage of the coverage was a fitting parameter during evaluation (the "covered surf." parameter gives the fraction of the illuminated area where the peptide layer is present). This means that besides thickness and optical properties of the layer the percentage of coverage was also adjusted during the fitting, and after finding the minimal MSE, the model provided these parameters. Since the binding of the peptide layer is weak in the case of n-type substrates, the amount of peptide deposited onto this surface is small as already reported by the $\Psi$ and $\Delta$ ellipsometric curves. Therefore, the optical dispersion properties of the peptide layers were fixed at the values observed for the p-type samples during the evaluation of n-type samples, too. The results of the ellipsometric evaluation with the not perfectly covering layer for $\mathrm{p}$ - and n-type samples are presented in Table 2 and Figs. 4 and 5. As $n$ and $k$ values were not fitted in the case of n-type samples these are not indicated in the table.

\begin{tabular}{|c|c|c|c|c|c|c|c|c|}
\hline Sample & $\begin{array}{c}n @ 532 \\
n m\end{array}$ & $\begin{array}{c}k @ 532 \\
n m\end{array}$ & $\begin{array}{l}\text { covered } \\
\text { surf. }(\%)\end{array}$ & $M S E$ & $\begin{array}{c}\text { effective } \\
\text { thickness }(\mathrm{nm})\end{array}$ & $\begin{array}{c}\text { covered surf. } \\
(\%)\end{array}$ & $M S E$ & $\begin{array}{c}\text { effective thickness } \\
(\mathrm{nm})\end{array}$ \\
\hline P1 & $1.52(0.10)$ & 0.0 & $\begin{array}{l}30.9 \\
(7.1)\end{array}$ & $\begin{array}{l}10.3 \\
(5.2)\end{array}$ & $5.7(3.5)$ & $2.5(0.4)$ & $6.2(0.4)$ & $0.6(0.1)$ \\
\hline $\mathrm{P} 2$ & $1.65(0.10)$ & 0.0 & $\begin{array}{l}25.7 \\
(2.4)\end{array}$ & $\begin{array}{l}14.9 \\
(5.0)\end{array}$ & $5.8(1.3)$ & $11.0(10.4)$ & $9.8(6.2)$ & $2.1(2.6)$ \\
\hline P3 & $1.54(0.02)$ & 0.0 & $\begin{array}{l}44.7 \\
(3.6)\end{array}$ & $\begin{array}{l}17.4 \\
(0.7)\end{array}$ & $10.6(1.2)$ & $5.1(0.5)$ & $5.5(0.5)$ & $1.1(0.1)$ \\
\hline P1-B & $1.66(0.12)$ & 0.0 & $\begin{array}{l}22.2 \\
(7.4)\end{array}$ & $5.6(1.7)$ & $2.8(1.5)$ & $8.2(4.9)$ & $4.7(0.9)$ & $1.3(1.1)$ \\
\hline P3-B & $1.63(0.12)$ & 0.0 & $\begin{array}{l}36.7 \\
(3.6)\end{array}$ & $\begin{array}{l}11.4 \\
(4.8)\end{array}$ & $6.5(1.2)$ & $4.2(1.1)$ & $5.7(0.8)$ & $1.0(0.4)$ \\
\hline PC4 & $1.56(0.02)$ & 0.0 & $\begin{array}{l}36.0 \\
(3.3) \\
\text { p-type Si }\end{array}$ & $7.0(0.8)$ & $5.7(0.6)$ & $5.2(0.2)$ & $\begin{array}{l}9.9 \text { (5.3) } \\
\text { n-type } \mathrm{Si}\end{array}$ & $1.1(0.1)$ \\
\hline
\end{tabular}


Table 2: Optical properties, thicknesses of peptide layers and surface coverage obtained from the ellipsometric model. Standard deviation is given in brackets.

By applying the patterned layer model, the mean square error drop to half compared to the previous model (see Supplementary information). The obtained MSE values are reasonable and indicate that the patterned character of the layer improved the modeling significantly. The refractive index dispersion of a typical Sellmeier-layer (for P3 peptide) resulting from this model is presented in Fig. 4. The extinction coefficient is zero by definition. The obtained optical properties are in accordance with literature data, further supporting that the patterned model describes properly the samples. ${ }^{32}$

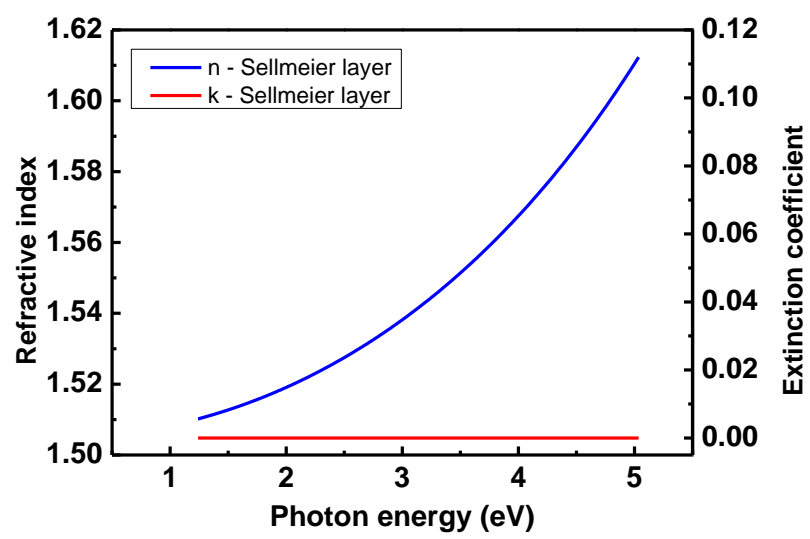

Fig. 4: Refractive index dispersion of the Sellmeier-patterned layer describing P3 peptide. Extinction coefficient is zero by definition.

Taking into consideration the surface coverages that are much lower for $\mathrm{n}-\mathrm{Si}$ (see table 2.) we can state that peptides generally adsorbed better onto p-type Si. The thicknesses were also obtained on the measured peptide layer patches (data not shown). While in case of a continuous thin film, the film thickness characterizes the amount of the deposited material, in case of the patterned model, a new quantity, the effective film thickness had to be introduced by multiplying the percentage of the covered area by the layer thickness. Naturally, the effective thickness would coincide with the thickness when the percentage of the covered area is 100. These 
effective film thicknesses calculated for the different peptides on p-type and n-type silicon substrates are listed in Table 2 and can be seen in Fig. 5. The obtained values indicate also that peptides prefer p-type silicon. In our previous theoretical simulation, we observed the exactly same phenomenon from the perspective of binding affinity in the order from $\mathrm{p}^{+}$-specific peptide to $\mathrm{n}^{+}$-specific peptide; SPGLSLVSHMQT (P3)> SVSVGMKPSPRP (P1) >LLADTTHHRPWT (P2). ${ }^{18}$ This indicates that the simulation can be well adopted in studying organic-inorganic interfaces for better designing of high affinity peptides.

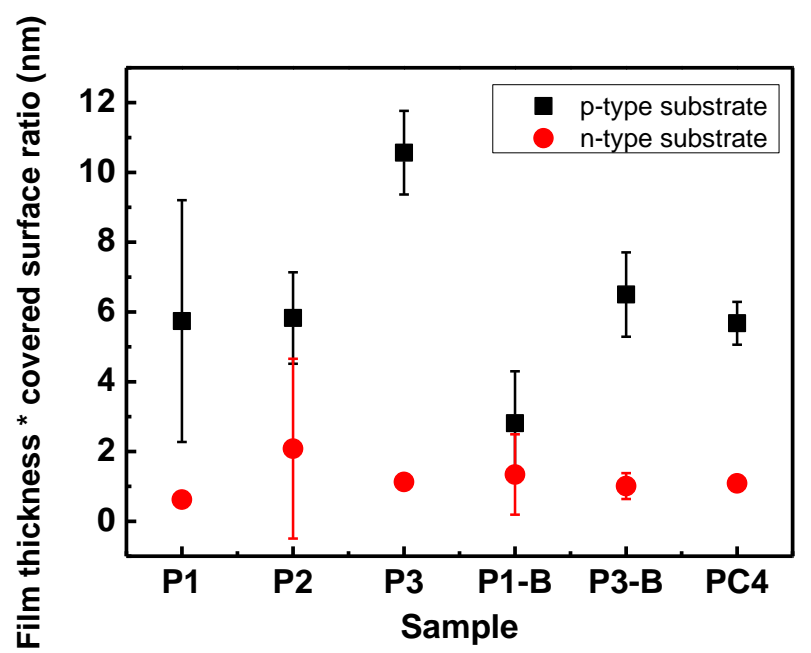

Fig. 5: Effective film thickness of peptide layers adsorbed on p-type (black squares) and n-type silicon substrates (red circles) as determined by ellipsometry

\subsection{Atomic force microscopic investigation of the peptide layers}

To complement our ellipsometry investigations with morphological information on the peptide layers atomic force microscopy (AFM) was employed. In particular, we used AFM in tapping mode to map simultaneously the shape, height and compositional variations of the adsorbed specific peptides on n-type and p-type Si surfaces. Fig. 6 presents AFM height (panels A, B, C and D), amplitude (panels E, F, G and H) and phase images (panels I, J, K and L) of P1, P2, P3 and PC4 peptides adsorbed on p-type Si surfaces. (For P1-B, P3-B adsorbed on p-type Si surfaces and P1, P2, P3 and PC4 peptides adsorbed on n-type Si surfaces, see supplementary information). Height or topography images enable to estimate both height (z) and lateral (xy) dimensions, thus to estimate peptide coverage of the Si surface. Amplitude images are similar to height images, but they display the shape of the specimen more clearly. They depict the map of 
the slope of the sample, showing how the tip is deflected as it encounters sample topography. Finally, phase images represent maps of how the phase of the cantilever oscillation is affected by its interaction with the surface, enabling compositional variations to be detected, which are otherwise unnoticeable in the height or amplitude images. The features depicted in the phase images exhibit the compositional variations within the explored area, evidencing the corresponding peptide and the Si substrate.

From these three types of images there is much information to be derived even without processing any quantitative analysis. First, it can be clearly seen that peptides do not form a homogeneous layer on the Si surfaces, supporting the applied ellipsometric model. Peptides form island-like structures with different lateral dimensions and heights. Phase images clearly demonstrate that the areas of larger heights in the topography images correspond to material having different composition than the Si surface. 

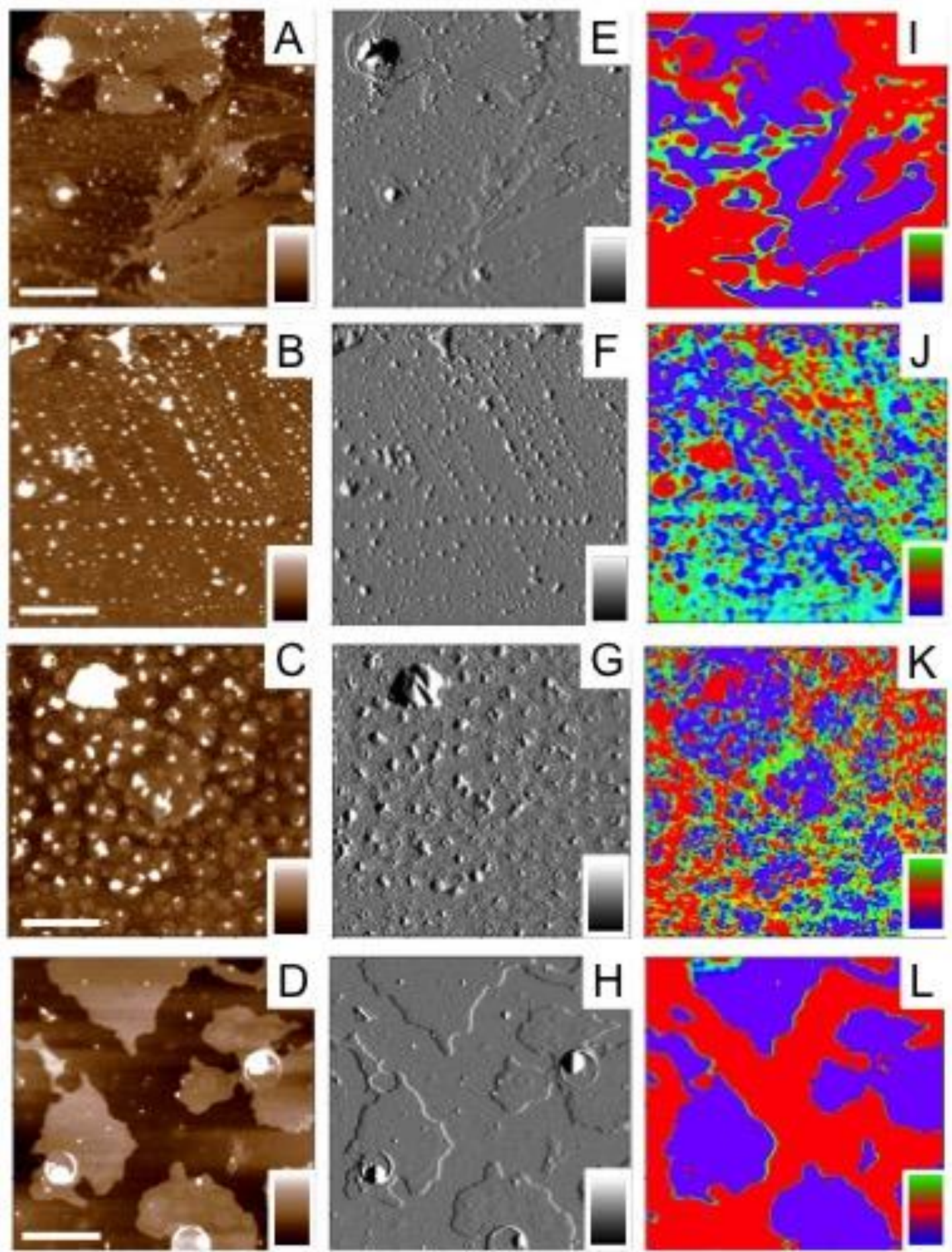

Fig. 6: AFM images: height (panels A, B, C and D), amplitude (panels E, F, G and H) and phase images (panels I, J, $\mathrm{K}$ and L) of P1, P2, P3 and PC4 peptides adsorbed on p-type Si surfaces, respectively. Height images enable to estimate both height and peptide coverage of the Si surface. Phase images give qualitative evidence of the compositional variations within the explored area of each sample. Color bars for height images range from 0 to 10 $\mu \mathrm{m}$, for amplitude images from 0 to $5 \mathrm{~nm}$ and for phase images from 0 to $5^{\circ}$. (Scale bars $=5 \mu \mathrm{m}$ ). 
Further we performed a detailed and quantitative analysis of height and surface coverage of the peptide films. Fig. 7 depicts corresponding height histograms to Fig. 6 A, B, C and D images. All histograms were fitted using one Gaussian distribution $\left(R^{2} \geq 0.97\right)$, providing the height of the layers formed by P1, P2, P3 and PC4 peptides on p-type Si.
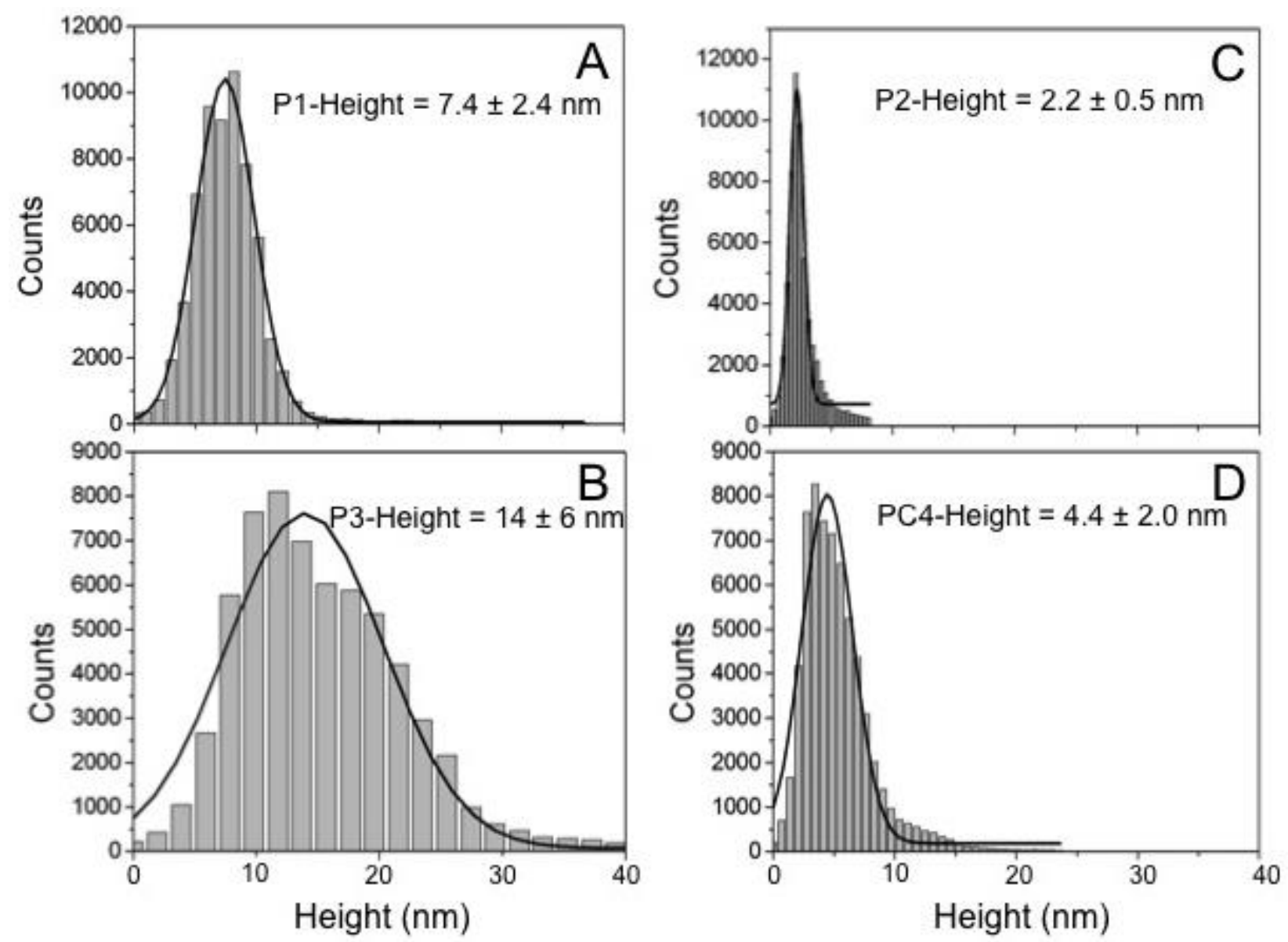

Fig. 7: Peptide layer height distributions on p-Si for P1 (A), P2 (C), P3 (B) and PC4 (D) petides. Histograms were fitted using one Gaussian distribution. Mean height values are also shown.

Covered surface ratios were also calculated when possible. These values were determined for peptides on p-type surfaces using height images shown in Fig. 6 and for peptides on n-type surfaces using images presented in the supplementary information. As height values were derived by averaging heights obtained on at least three different surfaces, these data indicate the effective thickness (modulated by the surface coverage) of the peptide layers. The results are gathered in Table 3 and the effective thicknesses are also presented in Fig. 8. 


\begin{tabular}{c|cc|cc}
\hline Sample & $\begin{array}{c}\text { effective } \\
\text { thickness }(\mathrm{nm})\end{array}$ & covered surf. (\%) & $\begin{array}{c}\text { effective } \\
\text { thickness }(\mathrm{nm})\end{array}$ & covered surf. (\%) \\
\hline P1 & $8.2(0.8)$ & 33.5 & $1.9(0.2)$ & 0.12 \\
P2 & $3.5(0.6)$ & 13.1 & $2.5(0.4)$ & 0.09 \\
P3 & $12.0(1.0)$ & 70.2 & $2.5(0.1)$ & 0.8 \\
P1-B & $3.3(0.5)$ & 18.7 & $2.0(0.1)$ & 7.3 \\
P3-B & $6.6(0.6)$ & 37.4 & $2.4(0.3)$ & 1.63 \\
PC4 & $5.3(0.4)$ & 28.6 & $2.1(0.3)$ & \\
\hline
\end{tabular}

Table 3: Effective thickness of peptide layers and percentage of surface coverage values obtained by AFM.

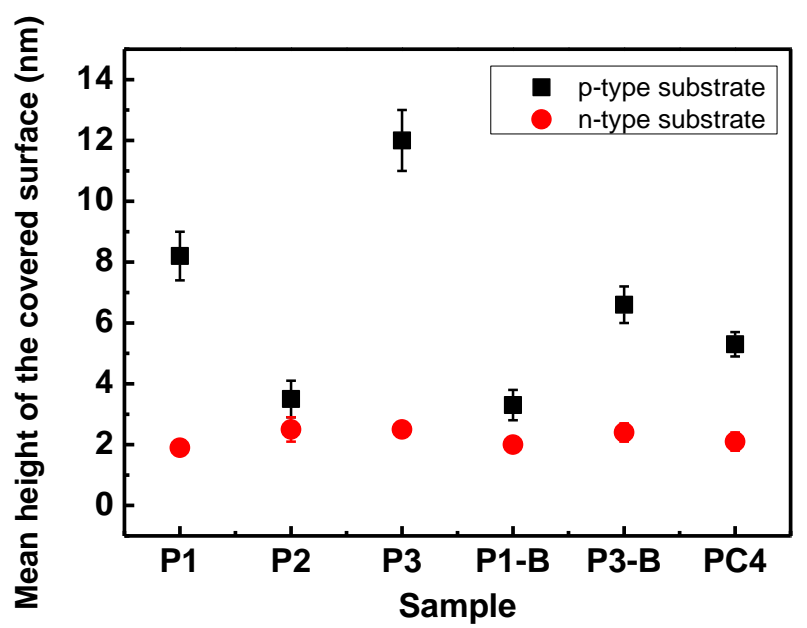

Fig. 8: Effective film thickness of peptide layers formed on p-type (black squares) and n-type silicon substrates (red circles), as obtained from AFM measurements.

The AFM results corroborate the ellipsometric conclusions, i.e. that the investigated peptides bind more effectively to p-type $\mathrm{Si}$ than to n-type. The observed surface coverage and film 
thickness correlate well with the results of the ellipsometry studies employing the patterned layer model

The effective film thicknesses follow the same tendency as observed in the case of ellipsometry investigations for both substrates (c.f. Figs. 5 and 8). Even though in case of p-type substrate the trends observed in thickness and coverage are similar for both AFM and ellipsometry results (c.f. Tables 2 and 3), the strict comparison of the results is not trivial as the ellipsometer measures regions much larger than those scanned by the AFM. In case of n-type substrates, such direct comparison of thickness and coverage does not reveal similarities since the amount of deposited material is so small that the optical data had to be fixed accompanied by increased uncertainty in the results. However, the effective thickness values in these cases can still be used to compare the results of the two measurement techniques. The peptides adsorb in very thin layers on n-type $\mathrm{Si}$ with a maximum of about $2.5 \mathrm{~nm}$ for P2 peptide, whereas they form thick layers on p-type Si up to about $12 \mathrm{~nm}$ for the P3 peptide, suggesting a multilayer assembling of these very small, sub-nanometric sized 12-mer peptides on the surface. Similar multilayer formation has been reported for peptide-mineral systems. ${ }^{37}$ Authors proposed that the formation of a monolayer of peptide requires the peptide concentration ranging from 0.05 to $0.2 \mu \mathrm{M}$ depending on peptide orientation. We have used higher, $20 \mu \mathrm{M}$ peptide concentration solutions for our experiment, the same as in our previous studies to get good detection limit for biosensing applications. The formation of the patched peptide islands indicates the different affinity of the studied peptides towards the p-type Si surface.

\section{Conclusions}

In this work, the adhesion differences of specific peptides to n- and p-type silicon have been investigated using spectroscopic ellipsometry. Since ellipsometry is an indirect characterization technique, AFM was also applied to support our findings. It was shown experimentally that binding of the investigated peptides is more effective in the case of p-type Si substrates, as expected from previous theoretical findings. ${ }^{18}$ We've proved that in cases when only the differences between the binding properties of several peptides are addressed, ellipsometry can provide valuable information even without evaluating the recorded data, just by comparing the $\Psi$ and $\Delta$ difference curves. It was presented that, if the amount of the deposited material is large 
enough (effective thickness exceeding $\sim 5 \mathrm{~nm}$ ), ellipsometry combined with patterned modeling can provide the optical properties, thickness and surface coverage of peptide layers. Furthermore, in cases when there is just a little adsorbed material, as for the n-type substrates, where the optical properties cannot be deduced, ellipsometry can still be used to determine the effective thickness of the films.

The presented results corroborate our previous theoretical findings ${ }^{18}$ and also the the experimentally determined binding efficiency of $\mathrm{Si}$ adhering peptides. ${ }^{29}$ Collectively, these results provide several meaningful parameters that play a critical role in peptide binding to Si. These data can be valuable when accurate hybrid force fields need to be developed for molecular dynamics studies of silicon-peptide hybrid materials.

Our work presents an evidence for spontaneous peptide multilayer assembly. Numerous are the papers reporting characterization of peptide self-assembly in the bulk solution, but much less work has been published on the interfacial self-assembly of short peptides in the vicinity of a planar surface. The advantage of short peptides is their ability to self-assembly to form various nanostructures that are attractive to many technological applications. Due to their structural complementarities, peptides adsorb and self-assemble at planar interfaces via electrostatic interactions, hydrogen bonding and hydrophobic effects. ${ }^{14}$ Anchoring various biomolecules through self-assembled peptides onto silicon might found promising applications when devices incorporating biological functionality are engineered.

\section{ASSOCIATED CONTENT}

Supporting Information. Supplementary figures. This material is available free of charge via the Internet at http://pubs.acs.org.

\section{AUTHOR INFORMATION}

\section{Corresponding Author}

Csilla Gergely 
${ }^{\#}$ To whom correspondence should be addressed. Csilla.gergely@univ-montp2.fr

\author{
Author Contributions \\ The manuscript was written through contributions of all authors. All authors have given approval \\ to the final version of the manuscript.
}

\title{
Funding Sources
}

Any funds used to support the research of the manuscript should be placed here (per journal style).

\section{ACKNOWLEDGMENT}

We are grateful for the financial support offered by the CNRS/MTA cooperation project Nr. 26126.

\begin{abstract}
ABBREVIATIONS
AFM, atomic force microscopy; BSA, bovine serum albumin; LC/MS, liquid chromatographymass spectrometry; NMR, nuclear magnetic resonance; PBST, phosphate buffered saline with Tween; SPPS, solid phase peptide synthesis.
\end{abstract}

\section{REFERENCES}

1. Chiu, C. Y.; Li, Y.; Ruan, L.; Ye, X.; Murray, C. B.; Huang, Y. Platinum nanocrystals selectively shaped using facet-specific peptide sequences. Nat Chem 2011, 3, 393-9.

2. Song, T.; Lee, S. T.; Sun, B. Q. Silicon nanowires for photovoltaic applications: The progress and challenge. Nano Energy 2012, 1, 654-673.

3. Sanchez, C.; Julian, B.; Belleville, P.; Popall, M. Applications of hybrid organic-inorganic nanocomposites. Journal of Materials Chemistry 2005, 15, 3559-3592.

4. Neiner, D.; Kauzlarich, S. M. Hydrogen-Capped Silicon Nanoparticles as a Potential Hydrogen Storage Material: Synthesis, Characterization, and Hydrogen Release. Chemistry of Materials 2010, 22, 487-493. 
5. Bogart, T. D.; Lu, X.; Korgel, B. A. Precision synthesis of silicon nanowires with crystalline core and amorphous shell. Dalton Trans 2013, 42, 12675-80.

6. Harraz, F. A. Porous silicon chemical sensors and biosensors: A review. Sensors and Actuators B-Chemical 2014, 202, 897-912.

7. Nel, A.; Xia, T.; Madler, L.; Li, N. Toxic potential of materials at the nanolevel. Science 2006, 311, 622-7.

8. Estephan, E.; Saab, M. B.; Agarwal, V.; Cuisinier, F. J. G.; Larroque, C.; Gergely, C. Peptides for the Biofunctionalization of Silicon for Use in Optical Sensing with Porous Silicon Microcavities. Advanced Functional Materials 2011, 21, 2003-2011.

9. de Jonge, L. T.; Leeuwenburgh, S. C. G.; Wolke, J. G. C.; Jansen, J. A. Organic-Inorganic Surface Modifications for Titanium Implant Surfaces. Pharmaceutical Research 2008, 25, 2357-2369.

10. Pantarotto, D.; Partidos, C. D.; Graff, R.; Hoebeke, J.; Briand, J.-P.; Prato, M.; Bianco, A. Synthesis, Structural Characterization, and Immunological Properties of Carbon Nanotubes Functionalized with Peptides. Journal of the American Chemical Society 2003, 125, 61606164.

11. Schwemmer, T.; Baumgartner, J.; Faivre, D.; Börner, H. G. Peptide-Mediated Nanoengineering of Inorganic Particle Surfaces: A General Route toward Surface Functionalization via Peptide Adhesion Domains. Journal of the American Chemical Society 2012, 134, 2385-2391.

12. Seker, U. O.; Demir, H. V. Material binding peptides for nanotechnology. Molecules 2011, $16,1426-51$.

13. Brown, S. Metal-recognition by repeating polypeptides. Nature biotechnology 1997, 15, 269-72.

14. Oren, E. E.; Tamerler, C.; Sarikaya, M. Metal recognition of septapeptides via polypod molecular architecture. Nano letters 2005, 5, 415-9.

15. Ramakrishnan, S. K.; Martin, M.; Cloitre, T.; Firlej, L.; Cuisinier, F. J.; Gergely, C. Insights on the facet specific adsorption of amino acids and peptides toward platinum. J Chem Inf Model 2013, 53, 3273-9.

16. Ramakrishnan, S. K.; Martin, M.; Cloitre, T.; Firlej, L.; Gergely, C. Design rules for metal binding biomolecules: understanding of amino acid adsorption on platinum crystallographic facets from density functional calculations. Physical chemistry chemical physics : PCCP 2015, 17, 4193-8. 
17. Heinz, H.; Farmer, B. L.; Pandey, R. B.; Slocik, J. M.; Patnaik, S. S.; Pachter, R.; Naik, R. R. Nature of molecular interactions of peptides with gold, palladium, and Pd-Au bimetal surfaces in aqueous solution. Journal of the American Chemical Society 2009, 131, 9704-14.

18. Ramakrishnan, S. K.; Martin, M.; Cloitre, T.; Firlej, L.; Gergely, C. Molecular mechanism of selective binding of peptides to silicon surface. J Chem Inf Model 2014, 54, 2117-26.

19. Tangney, P.; Scandolo, S. An ab initio parametrized interatomic force field for silica. The Journal of chemical physics 2002, 117, 8898.

20. Lopes, P. E. M.; Murashov, V.; Tazi, M.; Demchuk, E.; MacKerell, A. D. Development of an Empirical Force Field for Silica. Application to the Quartz-Water Interface. The Journal of Physical Chemistry B 2006, 110, 2782-2792.

21. Kermode, J. R.; Cereda, S.; Tangney, P.; Vita, D. A. A first principles based polarizable $\mathrm{O}(\mathrm{N})$ interatomic force field for bulk silica. The Journal of chemical physics 2010, 133, 94102.

22. Cruz-Chu, E. R.; Aksimentiev, A.; Schulten, K. Water-silica force field for simulating nanodevices. J Phys Chem B 2006, 110, 21497-508.

23. Garcia-Caurel, E.; Drevillon, B.; De Martino, A.; Schwartz, L. Application of Fourier transform infrared ellipsometry to assess the concentration of biological molecules. Appl Opt 2002, 41, 7339-45.

24. Schaferling, M.; Nagl, S. Optical technologies for the read out and quality control of DNA and protein microarrays. Anal Bioanal Chem 2006, 385, 500-17.

25. Hinrichs, K.; Gensch, M.; Esser, N. Analysis of organic films and interfacial layers by infrared spectroscopic ellipsometry. Appl Spectrosc 2005, 59, 272-82.

26. Mikhaylova, Y.; Ionov, L.; Rappich, J.; Gensch, M.; Esser, N.; Minko, S.; Eichhorn, K.-J.; Stamm, M.; Hinrichs, K. In Situ Infrared Ellipsometric Study of Stimuli-Responsive Mixed Polyelectrolyte Brushes. Analytical Chemistry 2007, 79, 7676-7682.

27. Kang, S.; Prabhu, V. M.; Soles, C. L.; Lin, E. K.; Wu, W.-1. Methodology for Quantitative Measurements of Multilayer Polymer Thin Films with IR Spectroscopic Ellipsometry. Macromolecules 2009, 42, 5296-5302.

28. Bachmann, M.; Goede, K.; Sickinger, A. G.; Grundmann, M.; Irbäck, A.; Janke, W. Microscopic mechanism of specific peptide adhesion to semiconductor substrates. Angewandte Chemie International Edition 2010, 49, 9530-9533.

29. Ramakrishnan, S. K.; Jebors, S.; Martin, M.; Cloitre, T.; Agarwal, V.; Mehdi, A.; Martinez, J.; Subra, G.; Gergely, C. Engineered Adhesion Peptides for Improved Silicon Adsorption. Langmuir : the ACS journal of surfaces and colloids 2015, 31, 11868-74. 
30. Woollam, J. A.; Johs, B. D.; Herzinger, C. M. Overview of variable-angle spectroscopic ellipsometry (VASE): I. Basic theory and typical applications. Proceedings of SPIE, CR72, 1999.

31. Fujiwara, H. Spectroscopic Ellipsometry. John Wiley \& Sons, Ltd: Chichester, UK, 2007.

32. Arwin, H. Adsorption of Proteins at Solid Surfaces. Springer-Verlag Berlin Heidelberg: 2014; p 29-46.

33. Herzinger, C. M.; Johs, B.; McGahan, W. A.; Woollam, J. A.; Paulson, W. Ellipsometric determination of optical constants for silicon and thermally grown silicon dioxide via a multi-sample, multi-wavelength, multi-angle investigation. Journal of Applied Physics $1998,83,3323$.

34. JA, W. Guide to Using WVASE32. J. A. Woollam Co., Inc: 2010.

35. Ruso, J. M.; Pineiro, A. Proteins in Solution and at Interfaces: Methods and Applications in Biotechnology and Materials Science; 1 edition ed.; Wiley: 2013.

36. Kovacs, N.; Patko, D.; Orgovan, N.; Kurunczi, S.; Ramsden, J. J.; Vonderviszt, F.; Horvath, R. Optical Anisotropy of Flagellin Layers: In Situ and Label-Free Measurement of Adsorbed Protein Orientation Using OWLS. Analytical Chemistry 2013, 85, 5382-5389.

37. Patwardhan, S. V.; Emami, F. S.; Berry, R. J.; Jones, S. E.; Naik, R. R.; Deschaume, O.; Heinz, H.; Perry, C. C. Chemistry of aqueous silica nanoparticle surfaces and the mechanism of selective peptide adsorption. Journal of the American Chemical Society 2012, $134,6244-56$. 
Insert Table of Contents Graphic and Synopsis Here

Interactions at the peptide/silicon surfaces - Evidence of peptide multilayer assembly

Zsuzsanna Pápa, Sathish Kumar Ramakrishan, Marta Martin, Thierry Cloitre, László Zimányi, Jessica Márquez, Judit Budai, Zsolt Toth, Csilla Gergely

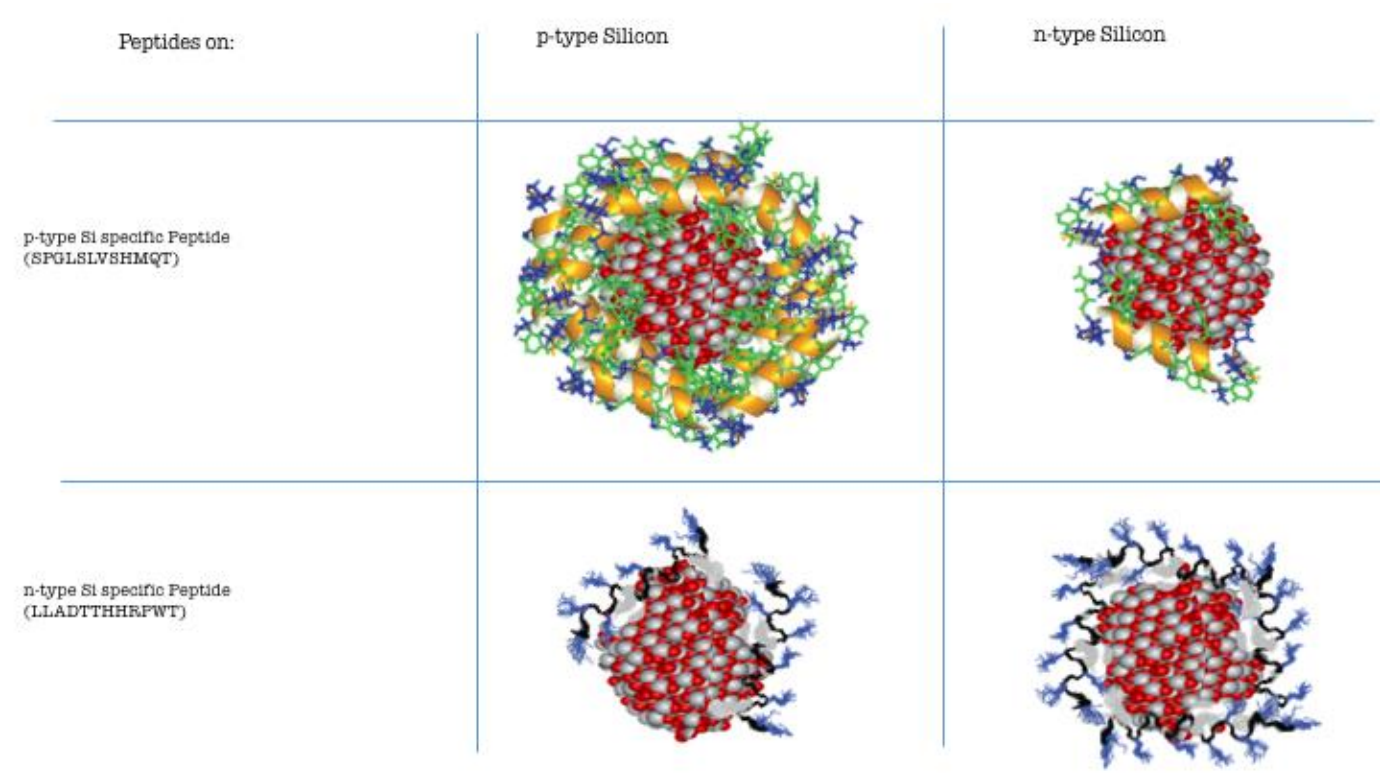

Schema on differential adsorption of specific adhesion peptides on p-, and n-type silicon. 